\title{
Business Process Reengineering: Strategic Tool for Managing Organizational Change an Application in a Multinational Company
}

\author{
Asli Goksoy (Corresponding author) \\ Department of Business, American University in Bulgaria \\ 1 Georgi Izmirliev Square, Blagoevgrad 2700, Bulgaria \\ E-mail: agoksoy@aubg.bg \\ Beliz Ozsoy \\ Siemens San.Tic.AŞ \\ 34870 Kartal, Istanbul, Turkey \\ E-mail:beliz.yilmaz@siemens.com \\ Ozalp Vayvay \\ Department of Industrial Engineering, Marmara University \\ Faculty of Engineering, Goztepe, Istanbul, Turkey \\ E-mail: ozalp@marmara.edu.tr
}

Received: August 4, 2011

Accepted: October 10, $2011 \quad$ Published: January 16, 2012

doi:10.5539/ijbm.v7n2p89

URL: http://dx.doi.org/10.5539/ijbm.v7n2p89

\begin{abstract}
Increased competition and globalization compels most organizations to become innovative and adopt change approaches. Business Process Reengineering is one of the most popular change management approaches that can bring incredible solutions to corporations. BPR has arisen as a solution for companies to improve their performances; elevate their efficiencies and gain a competitive advantage in this everlastingly developing and changing world. Even though there have been successful and unsuccessful cases stated in the literature, BPR has been touted as a vital management tool in order to achieve dramatic improvements and organizational competitiveness, if it is implemented properly and carefully. In this context; with this study, we analyze Business Process Reengineering as today's prominent management trend for organizational change, examine an reengineering project that has been undertaken in a multinational electronics and electrical equipment company, make suggestions for the areas that can be improved, and finally present survey results of employees` point of view regarding this project in their company.
\end{abstract}

Keywords: Business Process Reengineering (BPR), Organizational change, Human side of BPR, Employees reaction to change, Total Quality Management (TQM)

\section{Introduction}

Global competition has brought change. Consequently, in the era of hypercompetition, it is adequate to pursue the same or different goals via the same means (processes and resources as competitors). The very architecture the technological sequencing and time-honored partitioning of processes, is being redesigned, for example, reengineered (Zeleny, 2005). In today's highly competitive and constantly changing market place, in order to thrive and operate successfully, it is inevitable for companies to give up obsolete ways of doing business and adjust to changes in their environment. In recent years, "Business Process Reengineering (BPR)" became one of the most popular change management approaches which has attracted great attention from practitioners and academicians and has also become commonplace among companies. The main reason is an organization creates value through its processes, as BPR is purported to produce positive results for firms including improvements in critical, contemporary measures of performance, such as cost, productivity, service, customer satisfaction, and speed (Fliedner and Vokurka, 1997; Raymond et al., 1998) and can be used to bring about major internal and external quality increases, thus increasing value for both the employee and the customer (Dean, 1996). 
In today's business environment, there are so many reasons that force organizations go through change. Kotter and Schlesigner (1979) explained that with the increasing demands of government regulations, growth, competition, technological developments and changing workforce, most companies find that they must undertake moderate organizational changes at least once a year and major changes every four to five years. After 32 years, this statement is still valid, but also has a stronger value in truth. Recent studies point out that companies are driven to reinventing the corporation by one of three forces; desperation or crisis $(60 \%$ of cases); foresight (30\%); ambition (10\%) (Hammer, 1990). Among all, the changing economic environment has led to an increasing interest in business process reengineering by progressive firms around the world. One study shows that about $87 \%$ of firms surveyed were either engaged in BPR projects, or indicating their intention to take up BPR projects in the next few years (Ranganathana and Dhaliwal, 2001).

Business Process Reengineering has allowed many failing and even successful organizations to re-invent themselves to achieve performance improvements and position themselves in a better place in their markets. BPR involves reinventing processes by abolishing the old ones and finding imaginative ways of accomplishing work while designing completely and radically new processes. Consequently, BPR has arisen as a solution for companies to improve their performances by assuring a higher quality product at lower cost, larger added value and faster response time; elevate their efficiencies and gain a competitive advantage in this everlastingly developing and changing world: therefore, it became more than vital and worthwhile to investigate this concept and also to understand the whole process of BPR and its all stages.

The speed of rapid changes in the markets, shorter product life cycles and consumers' high expectations and demands require fundamental changes within an organization's structure, culture and other management processes. BPR is going to continue being a popular tool for change management in this decade, as BPR can be one of the best approach to challenge all the above mentioned factors, because a) BPR is about innovation and improvement; b) Process redesign and IT are essential ingredients of BPR (e.g. Thyagarajan and Khatibi, 2004) and that is also the cornerstone of today's business; c) it is extensively searched in the literature that BPR is about improving the cost, quality, service and speed. Research proves that many organizations that have undertaken reengineering projects report significant benefits from their BPR experience (Cafasso, 1993; Grover and Malhotra, 1995) in several areas, such as customer satisfaction, productivity and profitability (Goll and Cordovano, 1993).

BPR has a strategic value in managing organizational change, as it includes new vision or strategy: a need to build operational capabilities, need to reevaluate strategic options, enter new market or redefine products/services (Thyagarajan and Khatibi, 2004) and reflects the company's overall strategy (Browne and O'Sullivan, 1995). BPR derives its existence from different disciplines, and four major areas can be identified as being subjected to change in BPR-organization, technology, strategy, and people-where a process view is used as common framework for considering these dimensions (Leavitt, 1965). It is strategically important because it gives a new direction and hope for the organization's future, it is driven from top: it requires conceptual skills, strategic thinking and constant commitment from top level managers during all stages; from planning to implementation stages. The support, energy and drive of top management must also be sustained over a long period to ensure things actually done on time, effectively and efficiently. BPR will have short and long-term implications for an organization. Any process that is to be reengineered will not only have an impact on the function that has direct control over that process, but also other functions that will necessarily support the reengineered process. These two characteristics point to a strategic change for the organization (Sarkis et al., 1997). Lastly, some management experts defend reengineering as a necessary strategy for achieving higher levels of efficiency and effectiveness in knowledge work that has long been achieved in manufacturing (Wilkinson, 1991; Davenport and Short, 1990; Davenport and Stoddard, 1994; Hammer, 1996).

When it is about organizational change, specific attention needs to be given to employees, because it is people who make up organizations and it is they who are the real source of and vehicle for change; therefore, they are the ones who will either embrace or resist change (Smith, 2005). Human dimension is also an important factor in BPR and all employees will get affected directly or indirectly. Morris and Brandon (1993) have insisted on the commitment of the workforce in the implementation of business process reengineering, as full commitment of the workforce is the key factor in the successful implementation of BPR. A key challenge for managing change is to understand and control the attitude formation processes in the organization so that positive attitudes toward change are formed early in the change process and the formation of negative attitudes toward change is avoided (Lines, 2005). Like in all type of changes, it has been widely recognized that organizational and human, not technical barriers present the major challenges in BPR, although managers continue to be notoriously bad at recognizing those aspects of reengineering (Hammer, 1994). As a result of that tendency, people are often the first casualty of process reengineering (Marjanovic, 2000). In conclusion, it is critical to fully understand the 
human side of BPR in order to implement; complete the process and make it work successfully.

From a theoretical perspective, research on BPR contributes to our understanding of how organizations plan and implement BPR and by doing so, provide guidelines to others. Undertaking BPR is a high-risk, high-reward proposition. The payback for doing BPR correctly is enormous: $200 \%$ to $1000 \%$ improvements in key business performance measures are documented. But with those potential rewards comes high risks: studies show more than two-thirds of BPR attempts fail (Crowe et al., 1997). Although failure is not a targeted result, still companies such as American Express and Amoco were able to learn from earlier reengineering failures, and succeed on later attempts. It seems that "experience, more than the possession of the right approach or methodology is the key to reengineering triumph" (Cafasso, 1993).

Based on the mixture of results about BPR outcomes make the issue of BPR implementation very complicated and worthwhile to search. This study is both important and timely, because it represents a successful implementation in a multinational corporation in a highly competitive industry and provides detailed information about their BPR process with some further suggestions by the authors. This study is also unique, because it is not only establishing a solid structure about the technical aspect of BPR, but also the human side of this process including employees' perception, knowledge and satisfaction about this process. As it was mentioned earlier, without the participation and commitment of employees, even the best change plan will crumble, therefore, any findings related to employees' reaction will provide us some useful guidelines for the future studies.

\section{Literature review}

\subsection{Definition of organizational change}

In the general business domain, it has become increasingly apparent that strategies for organizational change have become an aphorism for maintaining success and creating competitive advantage in complex organizations (Wilson, 1992). Organizational change has traditionally been viewed as actions taken by organizations to alter their internal characteristics for better fit with their external environment (Lawrence, 1990). Organizational change is an empirical observation in an organizational entity of variations in shape, quality or state over time (Van de Ven and Poole, 2002) after the deliberate introduction of new ways of thinking, acting and operating (Schalk et al., 1998). The general aim of organizational change is an adaptation to the environment (Leana and Barry, 2000) or an improvement in performance (Boeker, 1997). Organization theory indicates organization change involve technology change, product change, administrative change and human resource change (Daft, 1989).

Hayes (2002) points out that modern life is increasingly becoming impermanent and transient because of the rapidly expanding scale and scope of change and its accelerating pace. This accelerating pace of change affects people's relationship with things, places, other people, organizations and ideas. It is argued that these changes demand a new level of adaptability for individuals and organizations.

Kottler (1996) mentioned in his book that over the next few decades a new form of organization emerge to cope with faster moving and more competitive environments and a new kind of employee will be seen and he believes that the most of the reengineering, restrategizing, mergers and cultural renewal projects will not disappear, but more and more organizations will be pushed to reduce costs, improve the quality of products and services, locate new opportunities for growth and increase productivity.

\subsection{Definition of business process reengineering (BPR)}

In today's ever-changing world, the business environment throughout the world is also going through a continuous and rapid change. Increasingly driven by consumers, change and competition, companies are now vigorously looking for new ways to make their organizations and businesses more efficient and competitive. They are analyzing and evaluating their current systems, structures and goals and are trying to find new solutions to their business problems. A new era started, when high-profile corporations such as IBM Credit Corporation and Taco Bell had come up with an amazing solution to improve their existing conditions: Business Process Reengineering (BPR). Followed by others [For example; Hallmark completely re-engineered its new-product process and Kodak's re-engineering of its black-and-white film manufacturing process cut the firm's response time to new orders in half (Hindle, 2008)], BPR proved to be a novel approach for corporate change, and continue its popularity since than.

The concept of reengineering traces its roots back to management theories developed in the early $19^{\text {th }}$ century. The purpose of reengineering is to "make all processes the best-in class". Fredrick Taylor suggested it as far back as the 1860's (Sturdy, 2010). But in 1990, the idea of re-engineering was first propounded in an article in Harvard Business Review by Michael Hammer. The method was popularly referred to as business process re-engineering (BPR), and based on an examination of the way information technology was affecting business 
processes. BPR's originators, Michael Hammer and James Champy maintained that re-engineering had a wider significance than mere processes. It applied to all parts of an organization and it had a lofty purpose. "I think that this is the work of angels," said Hammer in one of his more fanciful moments. "In a world where so many people are so deprived, it's a sin to be so inefficient." Their definition forms the cornerstone of this concept. They explained BPR as the fundamental rethinking and radical redesign of business processes to achieve dramatic improvements in critical, contemporary measures of performance, such as cost, quality, service and speed (Hindle, 2008).

BPR has numerous definitions made by different academic scholars and practitioners in literature. According to Lindsay and colleagues, BPR is a management tool, in which business processes are examined and redesigned to improve cost efficiency and service effectiveness (Grover and Malhotra, 1997). In the view of Doomun and Jungum, BPR is an organizational initiative to fundamentally re-examine and redesign business processes with the objectives of achieving competitive breakthrough in quality, responsiveness, cost, satisfaction and other critical process performance measures (Stahl, 1998). From Drucker's point of view (1993), reengineering represents a radical shift away from the tradition in which performance was primarily rewarded by advancement into managerial ranks, that is, the future holds very few "control" positions. In the ideal, reengineering company will not have hierarchy, but the idea of purposeful value added interaction. Talwar (1993) explains BPR as "the ability to rethink, restructure and streamline the business structures, process, methods of working management systems and external relationships through which we create and deliver value". Attaran and Wood (1999) commented that "the overall theme of BPR is the quest for improvement through quick and substantial gains in the organizational performance". The radical approach to BPR was pronounced as the only means of salvation for organizations trapped in outmoded and outdated business processes and general ways of working (Valentine and Knights, 1995).

Rather than a "quick fix," BPR is increasingly recognized as a form of organizational change characterized by strategic transformation of interrelated organizational subsystems producing varied levels of impact. The unique contribution of BPR over past organizational change approaches is its primary focus on the business process (Kettinger, et al., 1997). BPR means making radical changes to one or more business processes affecting the whole organization. It requires a cross-functional effort usually involving innovative applications of technology. Reengineering is an attempt to change the way work is performed by simultaneously addressing all the aspects of work that impact performance. This includes the process activities, people's jobs and reward system, the organization structure and the roles of process performers and managers, the management system, and the underlying corporate culture that holds the beliefs and values that influence everyone's behavior and expectations (Cypress, 1994).

BPR is process reintegration which is partially spontaneous process of responding to the extremes of specialization and division of labor. In BPR, the question to be asked is "Should we perform this operation at all?" before considering improving any operation, it needs to be absolutely clear that such an operation must be performed. The largest possible improvement to any operation-in terms of time, cost and reliability- must be its elimination (Zeleny, 2005).

In this highly complicated and competitive business world, reengineering should be facilitate the match between market opportunities and corporate capabilities and in so doing, ensure corporate growth. The principal aim of BPR is to design techniques to allow simulate and check different sets of processes that could improve its own organization (O’ Neill and Sohal, 1999).

The main elements of BPR are fundamental work process redesign, adding value to final customers, integration of cross-functional specialization, and exploitation of IT. The challenges of BPR initiatives are both technical and socio-cultural. It is technically problematic to develop radical process improvements. The socio-cultural challenge is in dealing with people's reactions to the likely serious organizational changes required (Reijers and Mansar, 2005).

Farrell (1994) provides a number of requirements for BPR to be successful: a) consistency between the company's business strategy and vision, and a clear understanding of customer, market, industry, and competitive directions, b) a management commitment to implement fundamentally different ways of conducting business, c) a business case that is founded on proven analytical approaches, and d) a project team with the capacity to evolve from simply conceptualizing change to actually developing and implementing it.

According to Hammer and Champy there are three possible situations that a company takes on reengineering; a) if the company needs dramatic improvement to survive, it needs reengineering (O'Neill and Sohal, 1999); b) the company may be doing quite well, but if management anticipates and expects some serious and threatening problems and competition in the near future, it needs reengineering; c) the company may be doing well and 
being in a peak condition, but if the ambitious and challenging management want to do better and make it more difficult for others to enter into the competition, it needs reengineering (Chan and Choi, 1997).

There are successful BPR implementations, however BPR projects, by their nature, entail major changes in business processes that may lead to organizational instability and failure (Ozcelik, 2010). Arthur D. Little consulting firm found that $85 \%$ of executives surveyed were not satisfied with the outcome of their BPR projects (Rock and Yu, 1994). Moreover, a series of studies in the early 1990s found that nearly $70 \%$ of BPR initiatives had actually failed (Kleiner, 2000) or delivered less than they had promised (Grover, 2000). Biggest obstacles that reengineering faces are: lack of sustained management commitment and leadership; unrealistic scope and expectations and resistance to change (Malhotra, 1998).

King (1994) views the primary reason of BPR failure as overemphasis on the tactical aspects and the strategic dimensions being compromised. He notes that most failures of reengineering are attributable to the process being viewed and applied at tactical, rather than strategic levels. Ozcelik (2010) listed some other reasons for poor BPR outcomes: (i) expecting too much too soon (Hammer and Champy, 2001), (ii) undertaking projects without a comprehensive cost-benefit analysis, (iii) lack of expertise on redesigning a set of related activities (Barua et al., 1996), and (iv) lack of partnership between internal information technology (IT) department and other parts of firms (Martinez, 1995).

\subsection{Pitfalls to avoid while conducting BPR}

2.3.1 Distinguish the re-engineering effort from the main goals of the organization

One of the common pitfalls which should be avoided while conducting a reengineering initiative is considering the reengineering initiative separate from organizational objectives. Reengineering efforts shouldn't be comprehended separate; on the contrary they should be seen as means of reaching organizational goals. That's why; companies should not take on reengineering projects without reference to their strategic aims.

\subsubsection{Underestimate the changes required to achieve a process orientation}

Lack of understanding about the tremendous upheaval which can result from implementing BPR is one of the reasons why firms need a second go. Too much attention to the process design phase and not enough on other aspects can result in a stalled initiative.

\subsubsection{Run before you can walk}

Companies which want to achieve dramatic performance improvements through BPR should prepare themselves for it and proceed with slow and confident steps. In other words, companies must be ready for the change which BPR will bring. The company's decision to implement BPR maybe be due to a history of TQM, a crisis situation or a visionary leader, but whatever the driver there must be a readiness for such a program.

\subsubsection{Do not expect too much too soon}

Change, in whatever form it takes, is a process that happens in time. For instance, changes such as cultural changes and changes in employees' behaviors and attitudes do not occur instantly. Not only change, but also benefits of change emerge in time. That's why companies should know that the real benefits of BPR may take some time to realize.

\subsubsection{Be careful about the title}

No matter what is called for the change program, it is the results that count and the important thing is the improvements that the change program brings (Peppard and Rowland, 1995).

\subsubsection{Over reliance on information technology}

While undertaking BPR projects many managers err in over relying on information technology solutions. They forget to analyze the business process and attempt instead to simply automate the ineffective process. Although IT is an enabler of business redesign the evidence shows that it is the business itself not the IT department makes the BPR projects successful (Chan and Choi, 1997).

\subsubsection{Pilot the new process}

Running a pilot process before implementing the new one helps identifying problems and bottlenecks related to the process and helps eliminating failures which are likely to happen. This kind of trial may take time and cost much but in case of the failure of the new process the time and cost in order to amend it would be much greater (Peppard and Rowland, 1995).

\subsubsection{Wrong process and objectives}

Defining a change objective wrongly and choosing a wrong process(es) which will not add great value to the organization's overall performance would result in reengineering failure (Chan and Choi, 1997). 


\subsection{Enablers of $B P R$}

BPR is a methodology which requires change in existing processes and designation of radically new ones and it is inevitable that some certain factors make this change feasible. These factors are known as enablers and may be defined as elements that act as vehicles for processes to change (Olalla, 1999). To be an enabler is to make able, to make feasible or effective, and to provide with means, opportunity, power, or authority (Chan and Choi, 1997).

\subsubsection{The role of Information technology (IT) in BPR}

Over the decades it has become evident that one of the most important ways to facilitate effective organization redesign through process engineering in organizations is through the use of information technology (IT) as an enabler of change. In fact, some have been willing to go beyond that by saying that IT is not only a key enabler of change, but also an initiator and a facilitator (Hammer, 1990; Chan, 2000).

IT can help making the changes promoted by reengineering, and it can be considered as an enabler of BPR. IT can be more than a useful tool in business process redesign. It can be said that IT and BPR have a recursive relationship. Each is the key to thinking about the other. Thinking about information technology should be in terms of how it supports new or redesigned business processes, rather than business functions or other organizational entities. And business processes and process improvements should be considered in terms of the capabilities information technology can provide (Davenport and Short, 1990).

IT should be viewed as more than an automating or mechanizing force, it can fundamentally reshape the way business is done. It is considered as both a strategic catalyst and enabler of process reengineering (Broadbent et al., 1999). Reengineering is about innovation and it also requires recognition of the new, unfamiliar capabilities of IT for rethinking business process instead of its familiar ones (Whitman, 1996). It therefore serves as one of the major facilitators for reengineering and the expected results will not actually be accomplished without its consideration (Grover and Jeong, 1995).

\subsubsection{Structural enablers}

Among numerous structural changes that can facilitate process reengineering, the most effective is the organizing of functional tasks into group-based units or teams (Love and Gunasekaran, 1997). Teams perform better as they integrate cross-functional skills in single work units. Furthermore, a broad set of skills and perspectives increases the likelihood that output will meet multifunctional requirements. For instance, new product development teams increasingly include representatives from all the functions involved in the product development process. One of the benefits of composing teams to aid process reengineering is that working in teams improves the quality of work life. Teams provide opportunities for small talk, development of friendships, social interaction and empathic reactions from other employees.

Although the execution of teams and team building have been underlined as the most important structural enabler of BPR, it should be recognized by the management that forming teams are not always vital to BPR, the work of individuals can also be effective. That's why, in order to figure out the best way of facilitating BPR, the organizational culture and functional diversity should be fully understood and analyzed by the top management before carrying out any structural changes (Love and Gunasekaran, 1997).

\subsubsection{Cultural enablers}

Greater empowerment and participation in decision making are some of the trends in organizational culture that have been recently noticed. These recent shifts have resulted in flatter organizational hierarchies or broader spans of control in organizations and have been widely documented to lead to both higher productivity and greater employee satisfaction. By this way, employees involved in the process become decision makers through greater empowerment and consequently taking responsibility for the functional and operational procedure of the process (Love and Gunasekaran, 1997).

\subsubsection{Human resources as an enabler of BPR}

Hammer and Champy recognize the importance of the human resource when they state "companies are not asset portfolios, but people working together to invent, sell and provide service." Based on this statement, we can state that human factor plays an important role in the daily operations, performance and consequently in the success of organizations.

No reengineering effort will succeed without first reeducating and retraining people who will ultimately work the new process. According to Meg Wheatly, "if you are going to move information and responsibility down to the low level, then the key question is how can you be sure that people will behave appropriately? You need to be sure that everyone is playing by the same rule book." (Brown, 1994). Hence, we can conclude that the success of BPR is closely linked to the success of human resources and human resource policies which act as an enabler for 
business process reengineering. The human resource enablers focus on new process skills, job motivation and human resource policies.

\subsubsection{BPR and Total Quality Management (TQM)}

Quality has been one of the strategic factors for organizations to be successful in the organizational world. Especially in recent years we witness many organizations adopting quality programs so as to ensure customer satisfaction in a highly perfect manner. With the importance that quality has gained for the last few decades of 20th century an important management concept called TQM has emerged.

Total Quality Management is an enabling ingredient that can contribute to the successful implementation of process reengineering. Essentially, TQM forms the foundations of process reengineering as it embraces open communications, and breaks down the barriers which exist between management and non-management personnel (Love and Gunasekaran, 1997).

Business performance improvement techniques include quality management, process improvement and process reengineering methodologies. The main difference is that quality management methodologies such as Total Quality Management, Six Sigma and process improvement techniques like the Japanese Kaizen, Lean, Total Productive Maintenance (TPM) among others focus on improving existing process whereas business process reengineering (BPR) brings about completely new processes. The radical approach to BPR was pronounced as the only means of salvation for organisations trapped in outmoded and outdated business processes and general ways of working (Valentine and Knights, 1998).

BPR is needed to help organizations go beyond the standard total quality management philosophies of incremental improvements to radical improvements. This philosophy is driven by increased global competition where major improvements in business processes are required merely to achieve competitive parity (Sarkis et al., 1997).

\subsection{BPR tools and techniques}

The various definitions of BPR suggest that the radical improvement of processes is the goal of BPR, but when we have a look at the literature we see that they do not refer specifically to the tools and techniques used in reengineering business processes. The result of this void is that some authors and consultants alike have pursued the use of many different tools in the search for the best reengineering application. These tools and techniques can be listed as below:

Process visualization: While many authors refer to the need to develop an ideal end state for processes to be re-engineered, Barrett (1994) suggests that the key to successful reengineering lies in the development of a vision of the process.

Process mapping and modeling: Process flowcharting, IDEF, role activity diagraming diagramming,etc.

Change management: Several authors concentrate on the need to take account of the human side of reengineering, in particular the management of organizational change. Some authors suggest that the management of change is the largest task in reengineering. Kennedy (1994) on the other hand, incorporates the human element of reengineering due to the perceived threat it has on work methods and jobs.

Benchmarking: Several authors suggest that benchmarking forms an integral part of reengineering, since it allows the visualization and development of processes which are known to be in operation in other organizations.

Process and customer focus: The primary aim of BPR, according to some authors, is to redesign processes with regard to improving performance from the customer's perspective.

Problem solving and diagnosis: Pareto diagramming, cognitive mapping, etc.

Process prototyping and simulation: Simulation has proven to be an effective tool in just about all facets of the reengineering process. It allows BPR practitioners to determine which processes should be reengineered and if proposed changes will have a productive impact. Simulation provides a structured environment in which they can better understand, analyze, and improve their processes (Hunt et al., 1997).

Project management: Budgeting, project scheduling, etc.

Process measurement: Activity-based costing, statistical process control, etc. It should be noted that few authors refer to any single technique when discussing BPR. Most incorporate and integrate a mixture of tools and techniques for change effectively and for the success of BPR projects.

\subsection{A proposed BPR methodology}

1). Identify the necessity for change: Any company contemplating on reengineering its processes should first recognize that a need for change is vital. Asking fundamental questions about the way business is done within 
the company, helps companies judge the way they operate and helps them detect whether a need for change is required or not.

2). Ensure top management's commitment and support: Having recognized the need for change it is also important that this necessity of change is approved by top management. Top management's commitment and support should also be gained and sustained over the orientation of the project through it's implementation to guarantee that things are done smoothly.

3). Communicate the necessity for change with employees: After getting the approval for the need for change from top management, this need should be communicated throughout the company so that employees can comprehend the company's strategy for the future, why change is needed, their role in it and benefits that the company will gain with reengineering. By doing this, the company can eliminate the resistance that may come from the employees.

4). Develop process objectives: In this step, organizations should determine the objectives they want to attain with business process reengineering. These desired objectives should ensure the company's vision and strategy to be accomplished and that's why should be compatible with them. These objectives which may be cost reduction, cycle time reduction, increase in quality, increase in speed or increase in market share etc. should be put in order in terms of importance for the company. It should also be borne in mind that the attempt of reengineering may require the company's vision to be redefined.

5). Form a reengineering team: During this step the reengineering team which will undertake the reengineering initiative should be formed. Here, the selection of competent team members is critical. That's why the right combination of people who are familiar with BPR concepts and with proper abilities and experience must be chosen. It is also crucial to describe the roles and liabilities of each team member explicitly so that they could completely comprehend their part in the project and dedicate themselves accordingly.

6). Determine the scope and scale of the project and develop a project schedule: Having identified the expectations from the BPR project along with the objectives the company wants to achieve with it, the next step is defining the scope and context of the project which is supposed to be consistent with these objectives and expectations. If a company -wide performance improvement is aimed then the scope and context of the BPR project must encompass the core processes that delivers value to target markets customers and stakeholders. In addition to that, team members should get together and set a project schedule which includes the duration time and also elaborates what will be done in each step of the project.

7). Designate the processes to be reengineered: At this step, dependent on the set BPR objectives and scope of the BPR project, the processes which need to be reengineered should be identified and prioritized in terms of redesign urgency and their contribution to these BPR objectives. Among these process alternatives the most significant processes are selected for redesign and "To-be" process models are developed.

8). Analysis and understanding of current processes: Even though some practitioners and researchers allege that the analysis of existing processes may undermine the creativity and imagination of team members on reengineering, it is momentous to understand the existing processes; process works flows fully and explicitly and identify non-value adding activities, bottlenecks and flaws in these processes before reengineering. Doing so, will enable that the problems in existing processes are not repeated in new processes.

9). Design the new processes: Having selected the processes to be reengineered and developed the feasible "to-be "process models, the next step is the redesign of these selected processes. While executing the redesign effort it is important to take into account the needs and recommendations of customers in target markets, suppliers or even logistics companies that the company may regularly work with. It should also not be forgotten that the overriding factor the company must consider while conducting the redesign effort, is fulfilling the needs and requirements of the customers and target markets more efficiently and effectively than its rivals.

10). Take advantage of IT: Information technology, as generally considered to be an enabler of business process reengineering sometimes may not be congruent to the current infrastructure of the company and must be altered in order to suit the newly designed processes. That's why IT elements needed to assist redesigned processes along with the requirements vital for the smooth transition from existing processes to new processes should be identified.

11). Include collaborators such as suppliers and freight forwarders in the reengineering initiative: As it has been witnessed in the reengineering initiatives carried out in SMS, cooperation with suppliers and even logistics companies while conducting BPR creates a collaborative atmosphere and ensures long term business relationships based on mutual trust which will be profitable and beneficial for both sides.

12). Pilot the new processes: Before the real implementation, performing a pilot version of the new processes 
will be beneficial. Because doing so will help some application problems to be detected ahead and solved accordingly. The aim of the pilot implementation is to overview the design of the new processes and to identify and overcome the potential flaws that might occur in the real implementation stage.

13). Train employees who have relevance with the redesigned processes: Communicating with employees before and during the reengineering project and training employees who will be directly involved in the newly designed processes will be very useful. At this point, the company should conduct training programs to ensure concerned employees acquire the necessary skills in order to operate the new process.

14). Implement the new processes: At this stage, the company should make a transition plan which will enable the smooth transition from the current process to the new process. Here, deciding on the type of transition is important. The type of transition may be a gradual transition or an overnight transition, but whatever the type of transition to the new system will be it is important to select the best way of crossing for the real implementation to be successful.

15). Monitor and improve the new processes constantly: Reengineering does not end with only redesigning existing business processes. Growing conditions of competition and continuously changing customer needs and requirements makes the continuous monitoring and improvement of redesigned processes compulsory for companies. That's why the effort of reengineering should be thought as a starting point instead of an end point if the company wants to gain competitive advantage over rivals and fulfill the needs and wants of target customers more efficiently and effectively.

\subsection{Human side of $B P R$}

The potential impacts of change on employees are significant: on the positive side, change can provide a wealth of opportunities for growth and development; but on the negative side, there can be substantial costs to negotiate new relationships, skills and patterns of activity (Kotter, 1995). In multiple and ongoing changes, such costs are likely to accumulate (Kiefer, 2005). Therefore, it is logical to say that organizational change has a range of beneficial and detrimental consequences for both employees and organizations.

Based on interpretations of and expectations about changes and how they perceive the change employees respond change differently (Mossholder et al., 2000). In most cases, employees either accept or oppose the change. Positive attitudes toward change and strong attitude-behavior links are expected to produce behaviors that are focused, persistent and effortful in their attempts to support and facilitate the implementation of the change. However, a basic assumption in much of the research is that organizational change is experienced in a negative way (Davy et al., 1988). Many have viewed change as negative for individuals, as it is generally expected negative consequences from change at the individual level, because the timing and nature of change is often in the best interest of the organization, resulting in asymmetries of motivation to change and benefits of change between organizations and their members (Wanous et al., 2000) and change tends to be disturbing for employees, particularly until the new order is fully normalized (Oreg, 2003). Other reasons may be listed as, (a) surprise or fear of the unknown, (b) mistrust of management, (c) a fear of failure, (d) loss of status or job insecurity, (e) peer pressure, (f) disruption of cultural traditions and group relationships, (g) personality conflicts with change agents and (h) a lack of tact and poor training of change agents (Kreitner and Kinicki, 1995).

The primary reason for BPR failure is resistance from key persons who would be affected by a BPR effort (Stanton et al., 1992). The reengineering involves change of roles, norms, standards, procedures, and work flows encompassed by a person's job in an organization. Every aspect of social organization is now subject to reengineering, including work processes; financial and governance structures; organizational culture; organizational designs; and organizational behavior. The traditional belief is that the basic reason for resistance in BPR projects is the fear of layoffs or the modification of power arrangements. Indeed, such factors seem to be part of the problem. Nevertheless, it is also necessary to understand the crisis reengineering may generate in individual's ongoing process of sense making (Moreno, 1999). Resistance by workers is also caused by the team-oriented approach, lack of ability to be adjusted to new technologies and process, vested interests and territorial disputes, skepticism about BPR results, and feeling discomfort of skill requirements as a result of BPR. Additional reasons for resistance can be managers' losing their power as a result of BPR since it flattens management layers, shift responsibility, and disrupts the status quo (Ahadi, 2004).

Marjanovic (2000) suggested the following strategies to be implemented in order to reduce resistance during BPR: Employees' attitudes towards the reengineering should be identified and reasons for resistance should be assessed, the threatening nature of BPR should be recognized, employees should understand the need for change, employee participation in the reengineering process is crucial and communication should be improved at all organizational levels.

Making employees feel they are part of the reengineering process can improve employee moral and soothe 
negative feelings. Assigning the most talented and strongest employees to the reengineering effort will have positive effect on performance and increase the radical redesign of business processes. Additionally, a good mix of team members from both inside and outside the process, as well as from outside the organization provides an ideal balance for success (Attaran, 2000).

Numerous researchers and practitioners believe that top management commitment is the most important factor for a successful BPR effort (Janson, 1993; Davenport, 1993). They argue that BPR never happens bottom up and a reengineered process alone will not change the way people work. It is clear that a strong leadership is essential during a BPR process, because leaders play a critical role in affecting BPR outcomes. It has long been known that leaders can literally 'make or break' a BPR project. Otherwise, lack of leadership can frequently cause for the high failure rate of business process projects. According to many experts, BPR implementation requires directive leadership style. Yet, it also requires the management of motivated, skilled, independent-thinking people doing non-programmable tasks for which a non-directive leadership style is most suited (Sutcliffe, 1999). Additionally clear, honest and frequent communication is also important for successful BPR implementation, because sharing information and empathizing with employee concerns can help minimize resistance (Janson, 1993).

BPR forces changes in management style. Reengineering forces managers to reevaluate not only what they do, but also who they are. Management must change the way it thinks, organizes, plans, deploys, inspires and rewards performance. They must learn to organize work in a holistic and integrated way (Attaran, 2000).

In conclusion, any significant BPR requires a strategic initiative where top managers act as leaders in defining and communicating a vision of change. The organizational environment, with a ready culture, a willingness to share knowledge, balanced network relationships and a capacity to learn should facilitate the implementation of prescribed process management and change management practices (Guha et al., 1997).

\section{Research design}

Based on the above research motives and relevant references in the literature, the research framework is an attempt to investigate the effects of BPR in production division in a multinational company. The information given here has been obtained from the interviews conducted with the company personnel and from the company's website (including Figure 1, 2 and 3). The figure 4 and all tables presented in this study were created by the authors based on their observation and calculations. The name of the company will not be denounced and it will be called SMS in the following sections. Additionally, employees' perception, knowledge, and satisfaction about this process are presented along with recommendations for future studies.

\subsection{Case study: SMS Company BPR Process}

SMS Company is a world leader company in electrical engineering and electronics and ranks second in sales among the world's leading electronics and electrical equipment companies. The company has been founded in 1847 and since that time it has tended to shape the future with innovations through its vision which is to sustain worldwide leadership in electrical engineering and electronics. SMS offers comprehensive range of systems, solutions and services and invests between 5-6 billion $€$ annually in global Research and Development (R\&D) SMS Company accounts to more than 1 million shareholders and employs over 400,000 people and is a global player with local access in more than 190 countries.

SMS activities in Turkey have started in 1856, but the foundation of SMS Inc. was eventuated in 1958. The company's former name was S-ko Inc. at that time, but with the transfer of $25 \%$ shares from one of the biggest Turkish groups to SMS AG, the name of the company was changed from S-ko Inc. to SMS Inc. The company's main mission is to strive for growth and increased value for stakeholders by implementing advanced technologies, new products and services to provide excellent solutions to satisfy customers' requirements. The company offers products, services and solutions in seven main areas: Power and infrastructure, information and communication systems, automation and control, transportation systems, medical solutions (IT and customer services), solutions (building technologies, industrial solutions, real estate, etc.) and program and system engineering.

Since SMS is a highly renowned company in manufacturing of energy control, energy distribution and consumption oriented electro mechanic products and devices, production management is at the core of SMS's all business activities. So, it is not overwhelming that reengineering efforts in production all focus on improving production. One of the main areas in which reengineering initiatives have taken place in SMS has been the production division of automation \& drives business unit.

3.1.1 Before re-engineering - historical perspective

Automation \& Drives business unit consists of two main sub business units which execute production: control 
and distribution (CD) and enstalation Technik- installation technique (ET). CD sub unit is specialized in producing contactor, signal lights, mini contactors, motor mechanisms, automatic switch appliances, thermic relays etc. ET, on the other hand is specialized in producing 05 to 70 ampere $\mathrm{B}$ and $\mathrm{C}$ type electric fuses that are used in homes and in industry. B type fuses are used in homes with the aim of lightening. C type fuses, however, are used in industry for motors and machines. The figure 1 depicts the production process in A\&D-CD simply.

\section{Insert Figure 1 here}

Before attempting on re-engineering, answers to some vital questions like: "Is there any need to change what is being done?, "How can the production process be improved and production times can be shortened?", "How flexibility to production orders could be ensured?" have been sought by the unit. As a result, putting a reengineering project named production storage areas project (PSA project) into practice has been decided. The purpose of the "PSA project" has been to form production storage rooms in the production site so as to give flexibility to production orders, constitute the necessary infrastructures to supply materials to this storage rooms free from orders and reduce production cycle time. Before the implementation of "PSA Project", the company was keeping a specified monthly based stock level in raw materials and semi-finished warehouse outside the production area and executing production depending on the yearly sales estimations which are set by the sales division.

Demands for every material needed to manufacture a certain product are logged into the SMS SAP R/3 4.6 C system that the company uses currently, on a yearly and monthly basis and these demands are revised in a meeting conducted every fortnight. As production orders were being received, raw materials and semi-finished goods were being transferred from the warehouses for raw materials and semi-finished goods outside the production area to the storage rooms in the production site. Here it is important to touch on that raw materials and semi finished goods warehouse outside the production area consists of semi-finished goods produced at pre-production, custom-made goods of which SMS provides the raw materials while other companies execute the production, and finally raw materials that are directly bought from some sale companies.

In addition to that before the implementation of "PSA project", in the former system, when a production order came from sales division to the warehouse division through SAP, the needed materials along with the availability of materials needed to produce a device was being checked and identified by the SAP system and if there was not enough material to manufacture a certain product first of all the system was providing a missing materials list and did not let the order/s open. After the system issued the deficient material list, this list was being given to the warehouse division which conveys the list to pre-production or procurement. After the materials in the list were complemented the production order/s were being opened and production was being commenced.

All these circumstances mentioned above resulted in long production phases and not sufficiently fulfilled customer requirements. Consequently, PSA project was a perfect solution to address these problems. The figure 2 designates the production process before reengineering.

\section{Insert Figure 2 here}

\subsubsection{Implementation of re-engineering in production}

The re-engineering project in the production department of SMS has 2 main objectives as shortening production times and satisfying customer requirements more efficiently in a short period of time by gaining production flexibility. In order to accomplish these goals the project named production storage areas and material supply project (PSA and MS Project) has been put into use. Within the framework of the project, production storage areas for raw materials and semifinished goods needed to manufacture certain items and shelves for each specific item in these production areas have been constituted in the production area.

All raw materials and semi-finished goods needed to manufacture certain products are stored in production storage areas called "PSA" in the production area with a particular code of 1100 . Raw materials and semi finished goods needed to produce a certain item are stored at shelves specific for each item in this production storage area with 1100 code. If we are to give a specific example: raw materials and semi-finished goods essential to produce "contactor" are stored on a different shelf and raw materials and semi-finished goods needed to produce "electric fuses "are stored on a different one.

Each unfinished product required to produce a certain product, on the other hand, is stored in a specific unfinished products storage area with a certain code. The code of unfinished products storage areas changes from device to device. For instance, unfinished products necessary to produce contactor are stored in a warehouse with a 1120 code. The stock quantities of unfinished products storage areas are determined based on yearly sales estimations and stocking is done on a weekly basis, but it can vary from product to product. For instance, the stocking of unfinished product "bobbin" which is necessary in producing "contactor" is done on a 15 day basis 
since any problem in bobbin line may cause a 15 day delay in production. The figure 3 briefly depicts the new process.

\section{Insert Figure 3 here}

Since the number of materials that are worked on is over 4,000 the stock tracking of materials and their supply from raw materials and semi-finished goods warehouse can not be done manually. That's why within the framework of the project a software program, PSA software-ABAP, independent from human power which works under the company's SAP program has been developed by information knowledge (IK) department. This system is supposed to provide materials from raw materials and semi-finished goods warehouse automatically.

The addresses where materials in the production area should be stored, packaging styles and the fixed quantity of each material are identified and are logged into the system. With this program maximum and minimum stock levels of PSA areas are identified and dispatch of related materials to these production warehouses without being dependent on order quantities has been ensured. The system enables the shipment of materials as previously determined groups. Every material is stored based on determined quantities and supplied from semi-finished warehouse as they reduce.

When we have a look at the working style of the software program, the program runs every night automatically, groups every material used in production based on their storage place in production and lists needed materials by working according to a stock formula which can be seen as: PSA stock-reserved quantity $<$ minimum stock level. If PSA stock minus reserved quantity which is the required quantity of materials for $100 \%$ confirmed orders, is less than the determined min stock level of that material the system calculates a quantity of need. For example: contact-PSA stock: 1,000, contact-reserved quantity: 500, contact-minimum stock: 600 , contact-maximum stock: 1,000 , the quantity of need: [maximum stock - (PSA stock-reserved quantity)]. In this example the quantity of need: $[1,000-(1,000-500)]=500$.

Having determined the quantity of need, the system uses a second formula to calculate the amount of materials that should be transferred from raw materials and semi-finished goods warehouse outside the production area to the PSA in the production area. This formula could be seen as: quantity of need $>1 / 2$ packaging quantity. According to this formula, if the quantity of need determined for a specific material is larger than half of the packaging quantity of this specific material previously described into the system, amount of materials to be sent to PSA should be the same as the multiples of packaging quantity. For instance: contact -packaging quantity: 250, quantity of need: $500,500>1 / 2250=500>125$.

According to this example, amount of contacts to be transferred to PSA is $250 \times 2=500$. These listings of these needed materials are made based on each device, according to device groups separately. For instance the contactor device involves different contactor groups such as K1, K2, etc. In addition to that, materials are listed according to their storage place in production. By this way needed deficient materials are taken from the warehouse and sent to production storage places.

The program could also be operated by a warehouse responsible manually in any time enabling the listing of missing materials to be identified. The warehouse responsible conveys the list to the operative warehouse responsible who collects and puts the needed materials from the raw materials and semi-finished goods warehouse so that the fork lift can take and carry them to the PSA.

If there is deficient stock or no stock at all for concerning materials in raw materials and semi finished goods warehouse, a notification mail is sent to the responsible people at production. These features of the new system granted important advantages which can be summarized as below:

* In the former system, for every order a dispatch report which included only one material was prepared and sent to the warehouse but in the new system every dispatch report sent to warehouse now includes at least 5 materials which in the end has ensured the reduction of paper need from 40,000 to 5,000.

* In the new system, materials from raw materials and semi-finished goods warehouse are now being demanded as the multiples of packaging quantities which reduced the material count processing by the warehouse staff. For instance, now instead of 6,300, 5,700 etc. 5,000, 10,000 numbers of materials packed are dispatched from raw materials and semi-finished goods warehouse.

* The going and coming number of the fork lift between raw materials and semifinished goods warehouse outside the production area and PSA in the production area has been reduced since max-min quantities of raw materials and semi-finished goods that are supposed to be in production area have been set with this new system.

* The employee need decreased from 17 to 10 .

* Deadline loyalty has been ensured and increased from $24 \%$ to $98 \%$ and customer requirements have been fulfilled on time efficiently. The time between starting and finishing of a specific order has decreased from 8.9 
days to 6 days.

\subsubsection{Proposes for further improvement}

When we have a look at the PSA project that has been put into use in A\&D-CD business unit, it seems to be working efficiently, but some recommendations could be made at this point with the purpose of aiding the business unit to operate more efficiently and cost effectively. The proposal for improvement that can be made for the production process of the sub business unit is to constitute "consignment stocks" for some of the raw materials. At this point, it is vital to mention that in SMS SAP system, every material bought from a supplier/sales company is described as "raw material" while materials that SMS have them produced to suppliers by providing them with raw materials and demands for labor work are described as "custom-made materials."

Every supplier/sales company which provides SMS A\&D-CD production unit with raw materials should have its own storage place for the products they provide in the production area with a particular storage code. Here, the sales companies or suppliers' task is to monitor the stock levels of SMS and supply materials as they reduce from their storage place.

In order to accomplish this, a web-based software tool, which will authorize and enable the suppliers to see and track the stock levels of SMS, should be established. As mentioned before, all the information related with raw materials (max-min stock levels, packaging quantities, storage no, supplier no etc.) had already been logged into the SMS SAP system. Based on the max-min stock level information entered to the system, a notification mail can also be sent to the suppliers as stock levels decrease from the identified min stock levels through SAP. At this point, it must be highlighted that since suppliers have the ability to monitor and track SMS stock levels they can adjust themselves and supply needed materials to SMS on time. Here it should be underlined that since "material income and transport" division will not control the materials supplied to the production area by suppliers, the quality of these materials ought to be secured with a "quality assurance agreement" made between SMS and the potential suppliers which will undertake the liability if any problem occurs in the production process of A\&D-CD because of low quality materials.

It must also be emphasized that since some of the identified raw materials will be provided directly into the production area by suppliers independent from the PSA Project; some adjustments in SMS SAP system should be made in order to effectuate the proposed system. The proposed system may look like Figure 4.

\section{Insert Figure 4 here}

Here it must be also emphasized that the terms of payment and supply are supposed to be set with an agreement made between SMS, contract manufacturers and sales companies. Since the proposed system is a "consignment stock system" the payment terms can be determined based on weekly material usage. If we were to give an example, if $150 \mathrm{~kg}$ of Molycote product which TEM Machine and Foreign Trade Inc. provides as an engineering adhesive is used in one week, a notification mail will be sent to TEM Machine and Foreign Trade Inc. and payment will be made on the basis of this $150 \mathrm{~kg}$ weekly usage. No payment will be done in advance; TEM will only receive payment as long as Molycote products are used by SMS weekly. We should also note here that a minimum weekly usage quantity must be also set ahead in the agreement and TEM should receive payment based on this minimum weekly usage quantity even its products are not used within a week. At this point, it will be useful to mention the estimated costs and savings SMS may have with this proposed system. These estimated costs, savings, and procurement figures which have been obtained from the purchasing specialists of A\&D-CD are summarized in the tables 1 and 2 .

Insert Table 1 here

Insert Table 2 here

The tables 1 and 2 show the estimated savings SMS will get, if the proposed system is implemented. Since the stock levels related with raw materials will be under the control of suppliers, there will be no need to place purchase orders to these companies. So, there will not be any need to print, fax and process these purchase orders by operative procurement in A\&D-CD.

In addition to the above mentioned savings related with procurement, the business unit will also reap the benefits of reducing its stock levels and will have the chance to reduce its' costs associated with high stock keeping since these stock levels will be monitored and supplied by suppliers. The approximate savings that will be gained through reduction in stock levels can be summarized as below:

* A\&D business unit invests approximately 5,000,000€ to its raw materials' stock which means that the amount of raw materials which are at stock in any time is approximately $5,000,000 €$. If the business unit opts to provide $50 \%$ of these materials through this proposed system, estimated saving will be around 2,500,000€. Here, it should be emphasized that the proposed system can not encompass $100 \%$ of raw materials since approximately 
$50 \%$ of them are imported from foreign countries.

- Since the business unit will invest half of the money it used to invest to raw materials' stock, the remaining half of the money which is $2,500,000 €$ could be invested to other risk free investment tools which is announced to bring nearly $16 \%$ revenue which means $400,000 €$ saving per year.

- The business unit will also take the advantage of decreasing its warehouse costs (area costs, personnel costs, transportation costs etc.) which is declared to be $5 \%$ of the money invested in raw materials' stock. This means $125,000 €$ saving per year.

According to the above estimated figures the approximate total saving can be calculated as $653,900 €$. At this point; as well as estimated savings, the costs that are likely to occur with this proposed system must be also alluded. According to the information obtained from IT and Logistics specialists in A\&D, the prospective costs that may occur can be designated as Table 3.

\section{Insert Table 3 here}

The figures in Table 3 prove that the business unit will have a significant amount of gain which can be stated as approximately $509.900,000 €$, if this proposed consignment stock system is put into use.

\subsection{Employees' perpective for BPR}

The purpose of the second part of this research is to assess employees' perceptions about the results of reengineering projects that have been carried out in SMS in terms of their consequences on both employees and the company; gauge the success of these projects from the employees' point of view and measure the employees' satisfaction with reengineering. This research's aim is to reveal how reengineering projects and their results are appraised by SMS employees and how employees are affected by reengineering initiatives carried out in their company. We believe the results of employees' perspective will provide valuable internal information to change agents in SMS and also provide guidelines for their future BPR.

The target population is the employees working in SMS/Turkey. The sample is drawn from this population which consists of 155 employees working as top manager $(n=8)$, middle level manager $(n=25)$ and non manager employee $(\mathrm{n}=122)$ in A\&D and PTD business units and who are related with BPR project. Based on the above topics the respondents were asked 20 questions (four of them are open ended questions and remaining ones are close-ended questions with multiple-choice options). By conducting surveys in person 80 responses were received, giving a response rate of $51 \%$. However, some of the respondents left too many questions unanswered, which dropped the sample size to 75 with a response rate of $\% 48$.

In these questions related with the above topics (question 5 to 12) respondents are required to indicate their extent of agreement with given statements on a five-point Likert scale (from $1=$ strongly disagree to $5=$ strongly agree). In questions q13 and q16 how employees rate the success of reengineering applications and their satisfaction with these applications used a five-point Likert scale (for q13: from $1=$ very unsuccessful to $5=$ very successful and for q16: from $1=$ very unsatisfied to $5=$ very satisfied). In questions q 4 and q 18, employees' perceptions on what reengineering is, were tried to be revealed. In questions q 17 and q 19, on the other hand, respondents were asked to designate their perceptions towards the factors that make reengineering projects successful and finally in q 20 respondents perceptions towards the degree of importance of success factors of reengineering in the reengineering projects that have been implemented in their company were tried to be measured.

The data analysis in the next parts is supposed to find answers to the following research questions:

* Do employees really know the term "Reengineering"?

* What are the perceptions of SMS employees about top management's commitment and support, employee efficiency, motivation and empowerment; achievement of aimed objectives, process simplification, customer satisfaction and information sharing which have assumed to come existence as a result of reengineering implementations?

* Are there any significant differences between manager and non-manager employee perceptions about the consequences of reengineering implementations?

* How do manager and non-manager employees rate the success of reengineering applications? How much manager and non -manager employees are satisfied with these applications?

* Which factors make reengineering applications successful from employees' point of view? How do employees rate the degree of importance of the mentioned success factors of reengineering in the reengineering projects in SMS?

In order to find answers to the above mentioned questions, sample and data characteristics reliability analysis, 
independent sample $\mathrm{T}$ test, chi-square analysis and correlation analysis are applied by SPSS 11.5 Software for Windows Release.

\subsubsection{Reliability Analysis}

In this survey, in order to determine the reliability level and internal consistency of the five-point Likert scale which consists of 10 variables the reliability co-efficient is found regarding the whole scale by using the Cronbach Alpha Internal Consistency Co-efficient and Guttman Split-half Co-efficient. At this point it should be noted that a reliability coefficient of 0.70 or higher is considered "acceptable" in most Social Science research situations. With the use of Cronbach Alpha test technique, the Cronbach Alpha value is estimated as 0.8768 . Since 0.8768 is higher than 0.70 , it can be said that reliability and internal consistency of the scale is high. The Cronbach Alpha and Guttman Split-half coeffficent values indicate that the reliability of the data used in this study is high and can be analyzed in this scope. The results can also be seen in the table 4 and 5 .

Insert Table 4 here

Insert Table 5 here

\section{Results}

\subsection{Analysis of perception towards top management commitment and support}

$2.7 \%$ of employees who responded the questionnaire strongly disagree, $1.3 \%$ disagrees, $10.7 \%$ neither disagree nor agree, $54.7 \%$ agree and $30.7 \%$ strongly agree that top management commitment and support has been ensured for the implementation of reengineering projects. Because of the fact that the variable "ensure of top management commitment and support" is presented as an interval scale in the survey, the mean is a good measure of central tendency for this variable. As a result, it can be deduced that most of the employees think top management commitment and support has been ensured for the implementation of reengineering projects.

\subsection{Analysis of perception towards employees' morale and motivation}

Because of the fact that the variable "employee morale and motivation" is presented as an interval scale in the survey, the mean is a good measure of central tendency for this variable. The mean is 3.53 and it designates that employee's perceptions towards the increase in employees' morale and motivation is positive. As a result, it can be deduced that $58 \%$ of the employees think employees' morale and motivation has increased after the implementation of reengineering projects.

\subsection{Analysis of perception towards empowerment}

$26.7 \%$ of SMS employees strongly disagree, $24 \%$ disagree, $12 \%$ neither disagree nor agree, $30.7 \%$ agree and $6.7 \%$ strongly agree that empowerment has increased after the implementation of reengineering. Because of the fact that the variable "empowerment" is presented as an interval scale in the survey, the mean is a good measure of central tendency for this variable. The mean is 2.67 and it designates that employees' perceptions towards the increase in empowerment is negative. As a result, it can be deduced that $50.7 \%$ of the employees think empowerment has not increased after the implementation of reengineering projects.

\subsection{Analysis of perception towards aimed objectives}

$1.3 \%$ of employees who responded the questionnaire strongly disagree, $5.3 \%$ disagree, $25.3 \%$ neither disagree nor agree, $57.3 \%$ agree and $10.7 \%$ strongly agree that aimed objectives have been accomplished after the implementation of reengineering. The mean is 3.71 and it designates that employees' perceptions towards accomplishment of aimed objectives is positive. As a result, it can be concluded that most of the employees think aimed objectives have been reached out after the implementation of reengineering.

\subsection{Analysis of perception towards process simplification}

$26.7 \%$ of employees who responded the questionnaire strongly disagree, $24 \%$ disagree, $6.7 \%$ neither disagree nor agree, $26.7 \%$ agree and $16 \%$ strongly agree that processes have been simplified after the implementation of reengineering. The mean is 2.81 and it designates that employees' perceptions towards process simplification is negative. As a result, it can be deduced that $50.7 \%$ of the employees think processes have not been simplified after the implementation of reengineering projects.

\subsection{Analysis of perception towards information sharing}

$4 \%$ of employees who responded the questionnaire strongly disagree, $4 \%$ disagree, $24 \%$ neither disagree nor agree, $54.7 \%$ agree and $13.3 \%$ strongly agree that information sharing has increased after the implementation of reengineering. The mean is 3.69 and it designates that employees' perceptions towards increase in information sharing is positive. As a result, it can be concluded that $68 \%$ of the employees think information sharing has increased after the implementation of reengineering. 


\subsection{Analysis of perception towards customer satisfaction}

$4 \%$ of employees who responded the questionnaire strongly disagree, $0 \%$ disagree, $30.7 \%$ neither disagree nor agree, $58.7 \%$ agree and $6.7 \%$ strongly agree that customer satisfaction has increased after the implementation of reengineering. The mean is 3.64 and it designates that employees' perceptions towards increase in customer satisfaction is positive. As a result, it can be concluded that $65.4 \%$ of the employees think customer satisfaction has increased after the implementation of reengineering.

\subsection{Analysis of reengineering success}

$1.3 \%$ of employees who responded the questionnaire have found reengineering implementations executed in SMS very unsuccessful, $16 \%$ unsuccessful, $12 \%$ neither unsuccessful nor successful, $65.3 \%$ successful and $5.3 \%$ very successful. The mean is 3.57 and it indicates that employees' perceptions towards the success of reengineering initiatives which have been carried out in SMS is positive. As a result, it can be concluded that most of the employees think reengineering implementations executed in SMS is successful.

\subsection{Analysis of reengineering satisfaction}

$2.7 \%$ of employees who responded the questionnaire are very unsatisfied, $12 \%$ unsatisfied, $14.7 \%$ neither unsatisfied nor satisfied, $65.3 \%$ satisfied and $5.3 \%$ very satisfied with reengineering implementations executed in SMS. The mean is 3.59 and it indicates that employees' satisfaction with reengineering initiatives which have been carried out in SMS is positive. As a result, it can be concluded that most of the employees are satisfied with reengineering implementations executed in SMS.

\subsection{Analysis of knowledge and agreement on the term of reengineering}

$93.3 \%$ of employees who responded the questionnaire agree with the definition of reengineering given, whereas $6.7 \%$ of them do not agree with it.

\subsection{Analysis of reasons for lack of success in reengineering implementations}

Among employees who responded this open end question, 38.5\% of them find reengineering implementations in SMS unsuccessful on the grounds that employees are not empowered enough as a result of BPR projects. Other reasons that were put forward by employees as lack of success in reengineering projects are, not adequately involving employees in the change management process, slow implementation, flaws that have come up with new programs or systems, insufficient planning, not sufficiently using IT, not considering the needs of other departments and lack of team working. Consequently, it can be asserted that among SMS employees who find reengineering implementations in SMS unsuccessful, most of them think that the reason for lack of success in these implementations is the fact that as a result of BPR implementations they are not empowered enough and their role in decision making mechanism is still limited.

\subsection{Analysis of reasons for success in reengineering implementations}

Among employees who responded this open ended question, $24.5 \%$ of them found reengineering implementations in SMS successful on the grounds that work efficiency has increased after these implementations. They claimed that with efficiency reengineering has provided; workflows have accelerated and eased up, paper work has decreased and process periods have been shortened. Other reasons for success in reengineering implementations which were broached by employees are need analysis, giving full weight to innovation, customer orientation, plan, report and control accurate change management, top management's support, information sharing and use of IT, communication with employees before and during the reengineering implementation, involving employees into the change management process and good results that have come up with reengineering projects. Consequently, it can be alleged that among employees who find reengineering implementations in SMS successful, most of them think that the reason for success in these implementations is the increase in work efficiency which is ensured by reengineering.

\subsection{Analysis of success factors in reengineering implementations}

Among the employees who responded the questionnaire $20 \%$ of them views top management support and team working as an important success factor of reengineering. In addition to that, $17.3 \%$ of the employees think that communication with employees during and before the implementation of reengineering projects is an important factor which makes reengineering implementations successful. The other success factors that were brought up by employees are increase in work efficiency, use of IT, experienced and specialized employees themselves, planning and resources, process analysis, innovative structure which attaches importance to new ideas and combines these with experience, cost, speed and time factors, use of proper methods and tools, customer orientation, control and continuous improvement of processes. Communication with employees before and during the reengineering implementations is perceived to be the overriding success factor of reengineering by $48 \%$ of employees. Besides, $34.7 \%$ of employees think that top management and support is the most important 
success factor of reengineering.

\subsection{Analysis of the importance of success factors in reengineering implementations in SMS}

$1.3 \%$ of employees think that the importance of top management and commitment as a success factor of reengineering in SMS is low, 5.3\% of them are neutral, $8.7 \%$ of them think it is high, and $34.7 \%$ of them think that the importance of top management commitment and support is extremely high in SMS as a success factor. $6.7 \%$ of employees think that the importance of customer orientation in SMS is low as a success factor of reengineering, $25.3 \%$ of them are neutral, $49.3 \%$ of them think it is high, and $18.7 \%$ of them think that the importance of communication with employees is extremely high in SMS as a success factor. $1.3 \%$ of employees think that the importance of IT in SMS is extremely low as a success factor of reengineering, $9.3 \%$ of them are neutral, $46.7 \%$ of them think it is high, and $42.7 \%$ of them think that the importance of IT is extremely high in SMS as a success factor. $93.4 \%$ of employees think that the company attaches high importance to "top management commitment and support" as a success factor of reengineering. $90.7 \%$ of employees think that the company gives high importance to "communication with employees" whereas $68 \%$ of employees have the opinion that the company gives weight to customer orientation as a success factor. Finally $89.4 \%$ of employees think that the company attaches high importance to IT as a success factor of reengineering. Top management commitment and support is given the utmost importance as a success factor of reengineering in SMS while communication with employees takes the second place and IT takes the third one in terms of importance from employees' point of view. Customer orientation seems to take the last place according to the figures obtained from the survey results.

\section{Conclusion}

In this study, today's one of the most popular change management concepts "Business Process Reengineering" has been examined as a change tool. The BPR applications related with production unit of a multinational company (SMS Company) as well as proposes for further improvement for these applications have been presented and finally a survey has been conducted with the company employees in order to assess their perceptions on reengineering applications which have been executed in their company. Survey results have exhibited that among 75 of employees who responded the questionnaire; most of them know what actually the term "Reengineering" is and agree with the reengineering definition that is mostly stated in the literature. The outcomes of the research have revealed that most of the employees are satisfied with reengineering implementations and find these implementations successful. Employees' perceptions towards reengineering applications executed in the company are that top management commitment and support has been provided for these applications, as a consequence of these implementations employee productivity, morale, motivation has increased, aimed objectives have been reached, and information sharing and customer satisfaction has augmented. Contrary to the expected consequences of BPR, employee empowerment has not increased and processes have not become simplier from the employees point of view.

Among employees who find reengineering implementations in SMS successful, most of them conceive these implementations as successful since work efficiency has increased after these implementations. Other reasons for success in reengineering implementations which have been put forward by employees are need analysis, innovation, customer orientation, plan, report and control, accurate change management, top management's support, information sharing and use of IT, communication with employees before and during the reengineering implementation, involving employees into the change management process and good results that have come up with reengineering projects. However, among employees who find reengineering implementations in SMS unsuccessful, most of them think that the reason of failure in these implementations is the fact that as a consequence of BPR implementations they are not empowered enough and their role in decision making mechanism is still limited. Other reasons that have been broached by employees as lack of success in reengineering projects are insufficient planning for BPR, slow implementation, flaws that have come up with new programs or systems, not involving employees in the change management process adequately, not using IT sufficiently, not considering the needs of other departments and lack of team working.

Key success factors of reengineering which have found out to be the most important ones are top management commitment and support, communication with employees, team working, and the composition of a suitable reengineering team and information technology from the employees' point of view. Other success factors which have been brought up by employees are increase in work efficiency, experienced and specialized employees themselves, planning and resources, process analysis, innovative structure which gives importance to fresh and creative ideas, cost, speed and time factors, use of proper methods and tools, customer orientation, control and continuous improvement of processes. Among the four success factors of reengineering which have indicated in the survey were the overriding success factor of reengineering, top management commitment and support, IT and customer orientation. 
When the importance given by SMS to above mentioned success factors of BPR is analyzed, it is seen that "top management commitment and support" is given the utmost importance as a success factor of reengineering in SMS while "communication with employees" takes the second place and "IT" takes the third one in terms of importance from employees' point of view. "Customer orientation" seems to take the last place according to the figures obtained from the survey results. In addition to the above mentioned findings, BPR projects which have been carried out in procurement, logistics and production divisions proved the importance of IT once more in supporting BPR.

The projects have also revealed that IT is the key enabler together with organizational enablers. Organizational enablers such as team working and empowerment are as important as IT in the success of BPR initiatives. However, survey results exhibited that empowerment is not sufficiently executed in SMS from the employees' point of view which may require top management to focus on this issue more in the near future.

\section{Discussion}

BPR is an effective management approach, adopted and applied widely by companies and can have very successful results, if implemented properly and diligently. Besides proper and careful implementation, there are also some other factors that play a significant role in the success of BPR projects. Commitment and support are important success factors in reengineering projects. If top management does not provide strong and consistent support in terms of capital, resources, or leadership over the life of the project, this weakens the BPR projects chance for success. Top management should also ensure constant control over the BPR projects to monitor how things are actually proceeding and to take action before any difficulty arises.

Communication is vital to the effective implementation of organizational change (DiFonzo \& Bordia, 1998). It is essential to provide the necesary and satisfactory information before change takes place and also during the change so that employees will have the accurate information and know what to expect from change with the right reasoning. As Smelzer and Zener (1992) mentioned in their study poorly managed change communication results in rumors and resistance to change, exaggerating the negative aspects of the change. Expressing the need for change and benefits that will be gained through reengineering before the implementation of reengineering project, helps employees have a thorough knowledge of the project, comprehend the necessity of change and as a result diminishes the resistance likely to come from employees.

The "reengineering team composition and team working" is also vital for the success of BPR applications. The reengineering team should be well organized and combine a mix of people and skills. IT is a major enabler and an essential element of most BPR projects and can give companies a competitive advantage by improving their competitive position. "Customer orientation" is also crucial for the success of reengineering initiatives. Since being customer oriented constitutes the essence of almost every company policy, it is inevitable for companies' reengineering efforts to aim at markets. That's why every reengineering effort should be directed to fulfill the needs and wants of customers in target markets.

In addition to the above mentioned success factors, for BPR projects to be successful it is also important that they are conducted in accordance with the company's overall strategy. If BPR projects and the company strategy do not complement each other, it is only possible to achieve short-term performance gains rather than long term performance improvements. That's why companies should thrive to ensure the harmony between BPR efforts and the company's strategy.

BPR projects also entail the good analysis of the current state and needs of the company and consequently identifying whether a need for change is really essential or not. Having identified the necessity for change, process(es) that needs to be altered should be identified. Contrary to the Hammer and Champy's approach which does not take into account the current processes while designing the new ones, we believe the existing process, process works flows, problems and bottlenecks associated with these processes should be analyzed well and they must be designed to bring away these problems. Analyzing existing processes and comprehending the underlying flaws related with these processes before the redesign stage does not limit the creativeness of the reengineering team on the contrary; it gives an insight about what can be done for improvement.

\section{Limitations of the study}

This investigation only uses the limited samples (only one company) to examine the BPR process and its effects on employees. Also, a wider survey with more questions could provide more information about employees' perspective on BPR process.

\section{Recommendations}

In this study, we use usable questionnaire responses from employees. We suggest the future research can collect information from both employees and management and/or change agents and compare the results to get more 
accurate information about BPR. Furthermore, future research also can use more case studies to compare the results of the BPR in different companies or sectors.

\section{References}

Ahadi, H. R. (2004). An examination of the role of organizational enablers in business process reengineering and the impact of information technology. Information Resources Management Journal, (17), 4, 1-19. http://dx.doi.org/10.4018/irmj.2004100101

Attaran, M. (2000). Why does reengineering fail? A practical guide for successful implementation. The Journal of Management Development, 19, 9/10; 794-801. http://dx.doi.org/10.1108/02621710010378237

Attaran, M., \& Wood, G. (1999). How to succeed at reengineering, MCB University Press. Management Decision, 37(10), 752-757. http://dx.doi.org/10.1108/00251749910302845

Barrett, J. L. (1994). Process visualization: Getting the vision right is the key. Information Systems Management, 11 (2), 14-23. http://dx.doi.org/10.1080/10580539408964631

Barua, A., Lee, B., \& Whinston, A. (1996). The calculus of reengineering. Inform Systems Research, 7(4), 409-28. http://dx.doi.org/10.1287/isre.7.4.409

Boeker, W. (1997). Strategic change: the influence of managerial characteristics and organizational growth. Academy of Management Journal, (40), 152-170. http://dx.doi.org/10.2307/257024

Broadbent, M., Weill, P., \& Clair, D. S. (1999). The implications of information technology infrastructure for business process redesign. MIS Quarterly, 23 (2), 159-182. http://dx.doi.org/10.2307/249750

Brown, T. (1994). De-engineering the Corporation. Industry Week, 18.

Browne, J., \& O’Sullivan, D. (1995). Reengineering the Enterprise. Chapman \& Hall, Galway, Ireland, 132-133.

Cafasso, R. (1993). Rethinking reengineering. ComputerWorld, 99-102.

Chan, L. C., \& Choi, C. (1997). A conceptual and analytical framework for business process reengineering. International Journal of Production Economics, 50, 212-214. http://dx.doi.org/10.1016/S0925-5273(97)00042-X

Chan, S. (2000). Information technology in business processes. Business Process Management Journal, 6 (3), 224-237. http://dx.doi.org/10.1108/14637150010325444

Crowe, T. J., Rathi, K., \& Rolfes, J. D. (1997). Selecting business process reengineering projects strategically. Computer Industry Engineering, 33 (1), 2, 157-160. http://dx.doi.org/10.1016/S0360-8352(97)00064-8

Cypress, H.L. (1994). Reengineering. OR/MS Today, 21, 18-29.

Daft, R. L. (1989). Organizational Theory and Design. St. Paul: West Publishing Company.

Davenport, T. (1993). Process Innovation: Reengineering Work Through Information Technology. Harvard Business School Press, Boston, MA.

Davenport, T. H., \& Short, J. E. (1990). The new industrial engineering: Information technology and business process redesign. Sloan Management Review, 11-27.

Davenport, T.H., \& Stoddard, D.B. (1994). Reengineering: Business change of mythic proportions? MIS Quarterly, 18, 121-7. http://dx.doi.org/10.2307/249760

Davy, J. A., Kinicki, A. J. Scheck, C. L. \& Sutton, C. L. (1988). Developing and testing an expanded model of survivor responses to layoffs: a longitudinal field study. Academy of Management Proceedings, 196-201.

Dean, E. B. (1996). Business process reengineering from the perspective of competitive advantage. [Online] Available: http://garcia1.larc.nasa.gov/dfca/bpre.html (Retrieved on June, 2011).

DiFonzo, N., \& Bordia, P. (1998). A tale of two corporations: managing uncertainty during organizational change. Human Resource Management, 295-303. http://dx.doi.org/10.1002/(SICI)1099-050X(199823/24)37:3/4<295::AID-HRM10>3.0.CO;2-3

Drucker, P. F. (1993). Post-capitalist Society. Butterworth-Heinemann, Oxford.

Farrell, J. (1994). A practical guide for implementating reengineering. Plan Review, 22 (2), 40-45.

Fliedner, G., \& Vokurka, R. (1997). Agility: the next competitive weapon. APICS--The Performance Advantage, 56-59.

Goll, E.O., \& Cordovano, M. E. (1993). Construction Time Again. CIO, 32-36.

Grover, K. W. (2000). Process Think: Winning Perspectives For Business Change in The Information Age. Harrisburg, PA: Idea Group. http://dx.doi.org/10.4018/978-1-87828-968-1 
Grover, V., \& Jeong, S. R. (1995). The implementation of business process reengineering, Journal of Management Information Systems, 12 (1), 109-144.

Grover,V., \& Malhotra, M. K.(1997). Business Process Reengineering: A tutorial on the concept, evolution, method, technology and application. Journal of Operations Management, (15), 193-213. http://dx.doi.org/10.1016/S0272-6963(96)00104-0

Guha, S., Grover, V., Kettinger, W. J., and Teng, J. T. C. (1997). Business process change and organizational performance: Exploring an antecedent model. Journal of Management Information Systems, 14, 1, 119-155.

Hammer, M. (1990). Reengineering Work: Don't automate, obliterate. Harvard Business Review, 69(4), 104-112.

Hammer, M. (1996). Beyond Reengineering: How the Process-Centered Organization Is Changing our Work and Lives. HarperCollins, New York, NY.

Hammer, M., \& Champy, J. (2001). Reengineering the Corporation - A Manifesto For Business Revolution. Harper Business, NewYork, USA, 35 -49.

Hayes, J. (2002). The Theory and Practice of Change Management. Basinstoke: Palgrave.

Hindle, T. (2008). Guide To Management Ideas and Gurus. The Economist In Association With Profile Books Ltd.

Hunt, K. L., Madigan Jr., E. F., Hansen, G. A., \& Richard A. P. (1997). Simulation success stories: Business Process Reengineering. Proceedings of the 1997 Winter Simulation Conference.

Janson, R. (1993). How reengineering transform organizations to satisfy customers? National Productivity Review, 12 (1), 45.53.

Kennedy, C. (1994). Re-engineering: the human costs and benefits. Long Range Planning, 27 (5), 64-72. http://dx.doi.org/10.1016/0024-6301(94)90228-3

Kettinger, W. J., Teng, J. T. C., \& Guha, S. (1997). Business process change: A study of methodologies, techniques, and tools. MIS Quarterly, (21), 1, 55-80. http://dx.doi.org/10.2307/249742

Kiefer, T. (2005). Feeling bad: antecedents and consequences of negative emotions in ongoing change. Journal of Organizational Behavior, (26), 875-897. http://dx.doi.org/10.1002/job.339

King, W.R. (1994). Process reengineering: The strategic dimensions. Information Systems Management, 11(2), 71-73. http://dx.doi.org/10.1080/10580539408964639

Kleiner A. (2000). Revisiting reengineering. Strategy and Business, (20), 27-31.

Kotter, J. P. (1995). Leading change: why transformation efforts fail. Harvard Business Review, (73), 2, 59-67.

Kotter, J. P. (1996). Leading Change. Boston, MA: Harvard Business School Press.

Kotter, J. P., \& Schlesinger, L. A. (1979). Choosing strategies for change. Harvard Business Review, (57), 2, 106-114.

Kreitner, R., and Kinicki, A. (1995). Organizational Behavior.( $3^{\text {rd }}$ Ed.). Irwin.

Lawrence, P. (1990). Why organizations change, in: A. M. Mohrman et al. (Eds) Large-Scale Organizational. Change, 48-61, San Francisco: Jossey-Bass.

Leana, C. R., \& B. Barry. (2000). Stability and change as simultaneous experiences in organizational life. Academy of Management Review, (25),753-759.

Leavitt, H.J. (1965). Applied organizational change in industry: Structural, technological and humanistic approaches, in: James March (ed.), Handbook of Organizations, Rand McNally, Chicago.

Lines, R. (2005). The structure and function of attitudes toward organizational change. Human Resource Development Review, (4), 1, 8. http://dx.doi.org/10.1177/1534484304273818

Love, P. E. D., \& Gunasekaran, A. (1997). Process reengineering: A review of enablers. International Journal of Production Economics, (50), 194-195.

Malhotra, Y. (1998). Business Process Redesign: An Overview. IEEE Engineering Management Review, (26), 3. Marjanovic, O. (2000). Supporting the 'soft' side of business process reengineering. Business Process Management Journal, (6), 1, 43-53. http://dx.doi.org/10.1108/14637150010313339

Martinez, E. V. (1995). Successful reengineering demands IS/business partnerships. Sloan Management Review, 36(4), 51-60. 
Moreno, V. (1999). On the social implications of organizational reengineering A phenomenological study of individual experiences of BPR processes. Information Technology \& People, 12, 4, 359-388. http://dx.doi.org/10.1108/09593849910301612

Morris, D., \& Brandon, J. (1993). Reengineering Your Business. New York: McGraw-Hill.

Mossholder, K. W., Settoon, R. P., Armenakis, A. A., \& Harris, S. G. (2000). Emotion during organizational transformations: An interactive model of survivor reactions. Group \& Organization Management, (25), 220-243. http://dx.doi.org/10.1177/1059601100253002

O' Neill, P., \& Sohal, A. (1999). Business process reengineering - a review of recent literature. Technovation, (19), 9, 574.

Olalla, M. F. (1999). Information technology in business process reengineering, Forthy-Seventh International Atlantic Economic Conference, Vienna-Austria, 583.

Oreg, S. (2003). Resistance to change: developing an individual differences measure. Journal of Applied Psychology. (88), 4, 680- 693. http://dx.doi.org/10.1037/0021-9010.88.4.680

Ozcelik, Y. (2010). Do business process reengineering projects payoff? Evidence from the United States. International Journal of Project Management, (28), 3, 7-13. http://dx.doi.org/10.1016/j.ijproman.2009.03.004

Peppard, J., \& Rowland, P. (1995). The Essence of Business Process Re-engineering. Prentice Hall, London, England, 237-244.

Ranganathana, C., \& Dhaliwal J. S. (2001). A survey of business process reengineering practices in Singapore. Information \& Management, 39 (2), 125-134. http://dx.doi.org/10.1016/S0378-7206(01)00087-8

Raymond, L., Bergeron, F, \& Rivard, S. (1998). Determinants of business process reengineering success in small and large enterprises: an empirical study in the Canadian context. Journal of Small Business Management, (36), $72-85$.

Reijers, H., \& Mansor, S. (2005). Best pracitces in business process redesign: an overview and qualitative evaluation of successful redesign heuristics. Omega, (33), 282-306.

Rock, D., \& Yu, D. (1994). Improving business process reengineering. AI Expert, 26 (10), $27-34$.

Sarkis, J, Presleyb, A., \& Lilesb, D. (1997). The strategic evaluation of candidate business process reengineering projects. International I. Production Economics, (50), 261-274.

Schalk, R., J., Campbell, W., \& Freese, C. (1998). Change and employee behaviour. Leadership \& Organization Development Journal, (19), 3, 157- 163. http://dx.doi.org/10.1108/01437739810210202

Smelzer, L. R., \& Zener, M. F. (1992). Development of a model for announcing major layoffs. Group and Organization Management: An International Journal, 17 (4), 446-72. http://dx.doi.org/10.1177/1059601192174009

Smith, I. (2005). Achieving readiness for organizational change. Library Management, 26(6/7), 408. http://dx.doi.org/10.1108/01435120510623764

Stahl, D. A. (1998). Reengineering: the key to survival and growth under PPS. Nursing Management, 29 (4), 162.

Stanton, S., Hammer, M., \& Power, B. (1992). From resistance to results:mastering the organizational issues of reengineering. Insights Quarterly: The Executive Journal of Business Reengineering, (2), 2, 6-16.

Sturdy, G. R. (2010). Business Process Reengineering: Strategies for Occupational Health and Safety. Cambridge Scholars Publishing.

Sutcliffe, N. (1999). Leadership behavior and business process reengineering (BPR) outcomes An empirical analysis of 30 BPR projects. Information \& Management, 36, 273-286. http://dx.doi.org/10.1016/S0378-7206(99)00027-0

Talwar, R. (1993). Business re-engineering. Long Range Planning, (26), 6, 22-40. http://dx.doi.org/10.1016/0024-6301(93)90204-S

Thyagarajan, V., \& Khatibi, A. (2004). BPR - A tool for managing the change. The Journal of Human Ecology, 15(1), 57-61.

Valentine, R., \& Knights, D. (1995). TQM and BPR: Can you spot the difference. MCB University Press, 27 (1). 78-85.

Van de Ven, A. H., \& Poole, M. S. (2002). Field Research Methods. In J. A. C. Baum (Eds.), Companion to 
Organizations. 867-888. Oxford: Blackwell Publishers.

Wanous, J. P., Reichers, A. E., \& Austin, J. T. (2000). Cynicism about organizational change: measurement, antecedents and correlates. Group and Organization Management, (25), 2, 132-153. http://dx.doi.org/10.1177/1059601100252003

Whitman, M. (1996). IT divergence in reengineering support: performance expectations vs. Perceptions. Information \& Management, (30), 5, 239-250. http://dx.doi.org/10.1016/S0378-7206(96)01046

Wilkinson, R. (1991). Reenigineering: Industrial engineering in action. Industrial Engineering, (23), 47-9.

Wilson, D.C. (1992). Strategy of Change. Routledge, London.

Zeleny, M. (2005). Human Systems Management: Integrating Knowledge, Management And Systems. World Scientific Publishing Co. Pte. Ltd. 91.

Table 1. Potential savings related with printing and faxing of purchase orders (yearly)

\begin{tabular}{|c|c|}
\hline Working days (yearly) & 300 \\
\hline Printing cost of 1 page $(€)$ & $0.09 €$ \\
\hline Number of purchase orders (yearly) x 2 pages per order & $5,000 \times 2=10,000$ \\
\hline Fax cost $(€)$ & $0.30 €$ \\
\hline Total Saving & $3.900,000 €$ \\
\hline
\end{tabular}

Table 2. Potential savings related with processing of purchase orders (yearly)

\begin{tabular}{|l|c|}
\hline $\begin{array}{l}\text { The cost of planning, opening, approving, sending, trailing and } \\
\text { ending of a purchase order }\end{array}$ & 30 Euro/hour \\
\hline $\begin{array}{l}\text { The duration of planning, opening, approving, sending, trailing and } \\
\text { ending of a purchase order }\end{array}$ & 50 Minutes \\
\hline $\begin{array}{l}\text { The cost of planning, opening, approving, sending, trailing and } \\
\text { ending of a purchase order }\end{array}$ & 0.50 Euro/minute \\
\hline The number of purchase orders related with raw materials (yearly) & 5.000 \\
\hline \multicolumn{1}{|c|}{ Total Saving } & $\mathbf{1 2 5 . 0 0 0 , 0 0 0} €$ \\
\hline
\end{tabular}

Table 3. Potential costs related with the proposed consignment stock system (yearly)

\begin{tabular}{|l|l|}
\hline The cost of the software tool $(€)$ & $\sim 50.000 €$ \\
\hline Supplier training and development costs $(€)$ & $\sim 3.000 €$ \\
\hline The cost of supplier support $(€)$ & $\sim 1000 €$ \\
\hline Storage costs $(€)$ & $\sim 90.000 €$ \\
\hline Total cost & $\sim \mathbf{1 4 4 . 0 0 0 , 0 0 0} €$ \\
\hline
\end{tabular}

Table 4. Reliability Analysis with Cronbach Alpha Technique

$$
\begin{aligned}
& \text { Reliability Analysis -Scale (Alpha) } \\
& \text { Reliability Coefficients } \\
& \text { Number of Cases }=75.0 \\
& \text { Alpha }=.8768
\end{aligned}
$$

\begin{tabular}{|c|c|}
\hline Reliability Analysis -Scale & If ) \\
\hline Reliability Coefficients & \\
\hline Number of Cases $=75.0$ & \\
\hline Guttman Split-half $=.8291$ & Number of Items $=10$ \\
\hline Alpha for part $1=0.7890$ & Alpha for part $2=0.8088$ \\
\hline
\end{tabular}$$
\text { Number of Items }=10
$$

Table 5. Reliability Analysis with Split-half Technique 


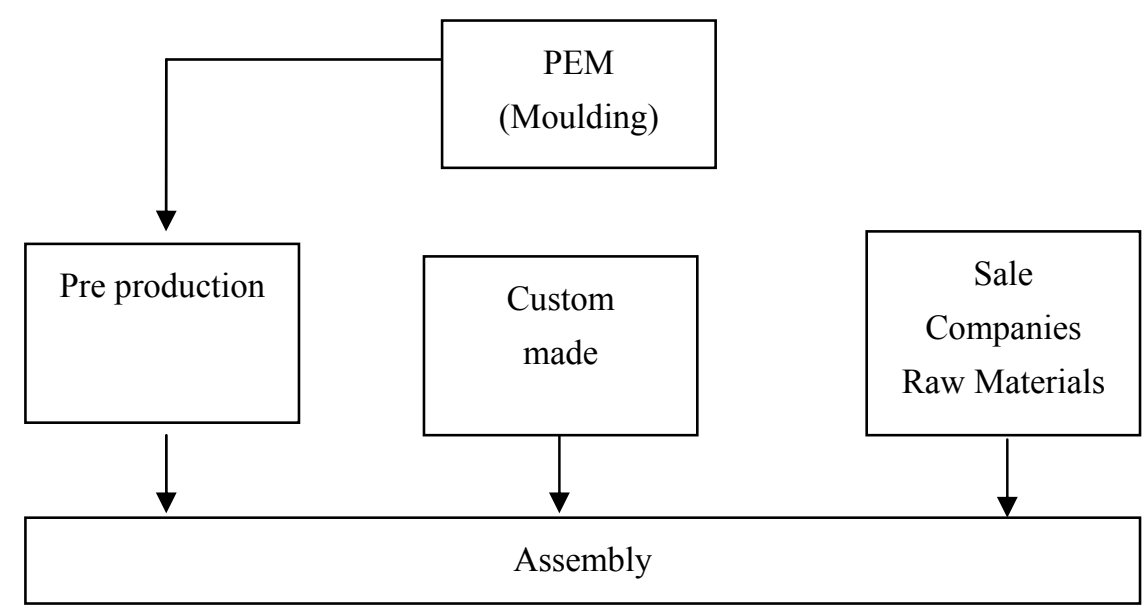

Figure 1. Production process in A\&D-CD simply

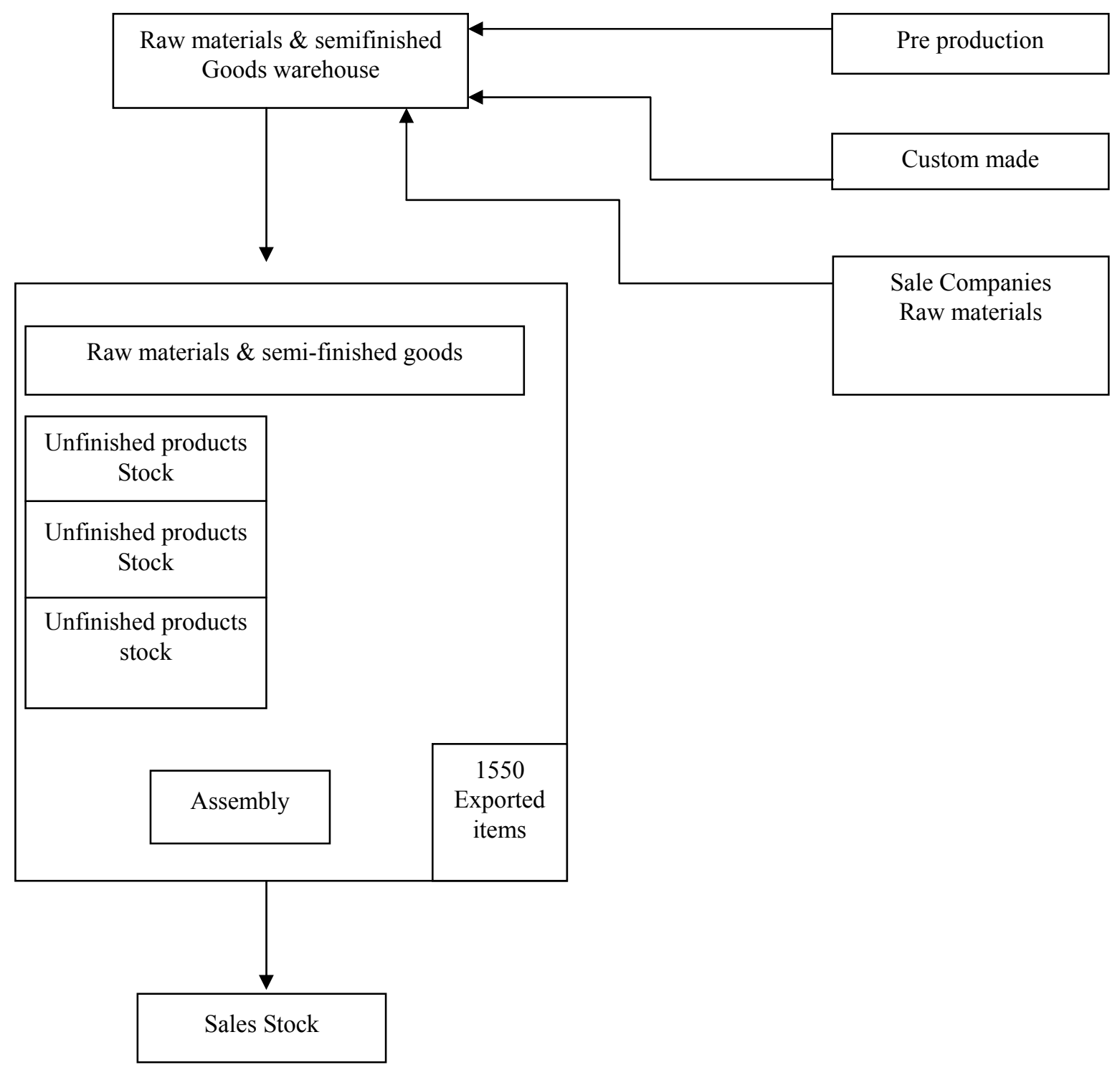

Figure 2. The production process before re-engineering 


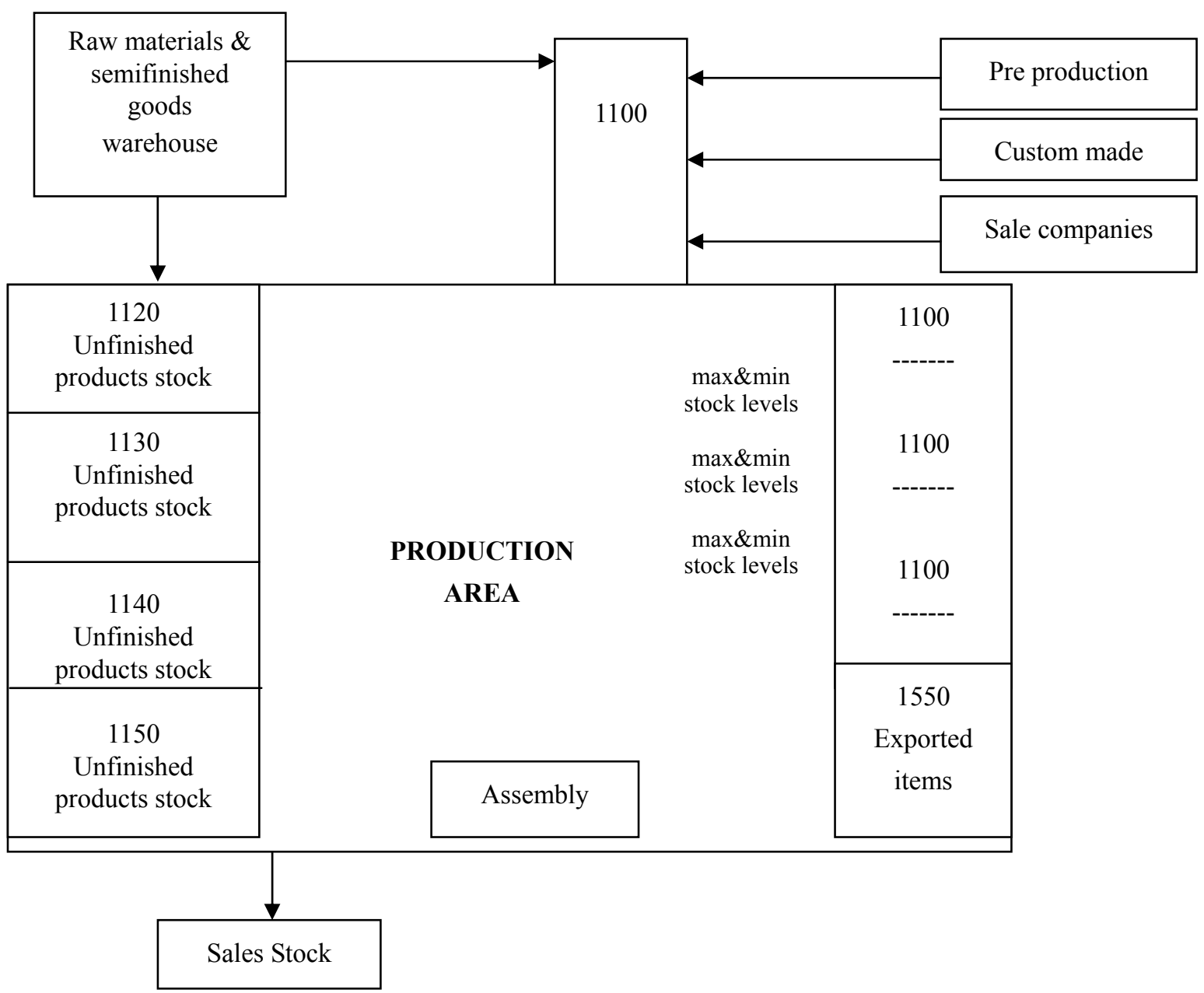

Figure 3. The production process after re-engineering

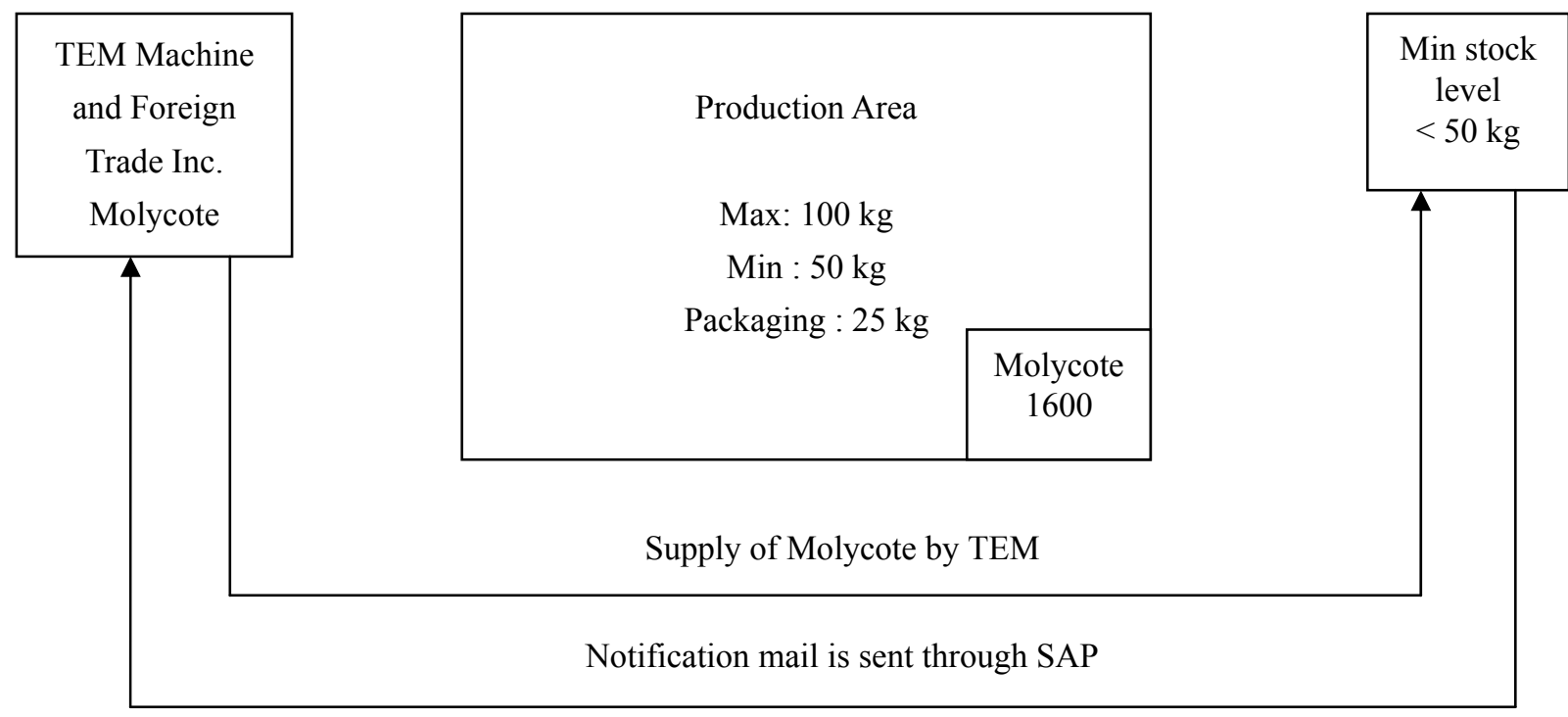

Figure 4. The proposed consigment stock system 